\title{
Perspectives on patients and service users and carers in leading teaching roles in interprofessional education
}

\section{Anderson ES. Ford J, Thorpe, $\mathrm{N}$}

\section{Abstract}

The involvement of patients and carers is central to the values of interprofessional education (IPE) which aims to improve the experience of care and care delivery. Partnership arrangements with service users and carers within Higher Education Institutions face the same barriers relating to status, power and resources, as the implementation of IPE. The complexity of these alignments can be explained by Activity Theory (AT). Using a qualitative research methodology we set out to consider the stakeholder perspectives on whether patients should progress from telling their stories to taking on a leading teaching role, within a well-established IPE workshop. Following the principles of Participatory Action Research, data were collected cyclically, using consultation meetings, interviews (with tutors and patients) and focus groups (with students). The work was overseen by a steering group who reviewed and clarified the analysis, informed by AT. All stakeholders endorsed the validity of patients as teachers. Two new leadership roles were proposed; patients as Co-Tutors and as Mentors supporting the workshop. Service users and carers were realistic about the support required for progression. Students were more ambivalent, recognising the right of patients to tell their stories but having concerns about their competence and potential bias when in leading roles. There is overall support for the development of a progressive route for patients to move beyond telling stories into leading teaching roles in IPE but this brings added complexity and requires a supportive infrastructure, careful preparation of students and further research. 


\section{Perspectives on patients and service users and carers in leading teaching roles in interprofessional education}

\section{Introduction}

Interprofessional education (IPE), underpinned by pedagogical theory, involves sharing expertise across professions and places service users and carers* at the centre of learning (World Health Organisation, 2010; Kilminster et al., 2004; Barr, et al., 2017). The value of partnership arrangements for learning with and from service users and carers is reflected in international consensus policy directives (Australian Commission, 2012; Health Canada, 2007; Department of Health UK, 2010) and within the UK in national regulatory frameworks (National Health Service 2014; General Medical Council, 2011; Nursing and Midwifery Council, 2010; Health and Care Professions Council, 2016). The need for compassionate, patient-centred care and "patient-centred professionalism" is well established in the literature and more should be done to grow this compassion from the earliest days in undergraduate preregistration education (Chochinov, 2007; Higginson \& Hall, 2007; Hutchings, 2012). Patient involvement in professional training programmes is seen as a solution for developing compassionate professionals and remains essential when drivers for change endorse user involvement at all organisational levels for care delivery (Spencer, Godolphin, Karpenko \& Towle, 2011; Francis, 2013).

\footnotetext{
* The terms patient and service user will be used interchangeably throughout this paper to represent the many terms used. Where these terms are used they refer also to carers of people who use services.
} 
Embedded involvement of service users across the spectrum of educational activities is well established in mental health nursing and social work (Tew, Gell \& Foster, 2004; Beresford et al., 2006). However, patient involvement in medical education currently takes the form of local initiatives lacking a systematic body of theoretically informed evidence (Spencer, 2016). In many cases passive patient involvement characterised by "paternalism" and "medical gaze" is the norm and there are fewer examples of true partnerships with patients in leading teaching roles in medical education (Regan de Bere, \& Nunn, 2016). Although a recent review highlights progress towards collaborative partnerships for patient involvement in health and social care education, concerns are identified for institutional support, patient representativeness and funding (Towle et al., 2016)

Interprofessional learning (IPL) has similar but more complex challenges relating to the different perspectives of student professions and the large cohorts involved. In the 'Learning from Lives' programme, tensions emerged when medical and social work students' values collided as they worked together to address the complex needs of disabled people (Anderson \& Smith, 2010). In all types of professional education, be it uni-professional or interprofessional, much of the learning currently involves patients in a story telling role rather than a true partnership relationship as envisaged in the early citizen engagement movement (Arnstein, 1969). In the UK there are examples of insights into successes and best practice involving true community engagement (McKeown, Malihi-Shoja \& Downe, 2010). 
Patient involvement in undergraduate professional curriculum to some extent mirrors the challenges faced when setting up IPL. These relate to differences in power relationships, communication styles, values and the need to merge systems for patient involvement within educational processes (Gilbert, 2005). Partnership arrangements require faculty support and resources combined with faculty development, concerning the emotional vulnerability that patients and carers may encounter when sharing personal experiences (Spencer, Godolphin, Karpenk \& Towle, 2011). Support mechanisms should be in place for all parties to prepare for the exchanges that will take place; especially when these are face-to-face in real time. These complex challenges for authentic partnerships with patients in professional education, requiring the recognition of equal value and status within faculty, can be explained using system theories, such as complexity theory (Barr, 2013; Cooper Braye \& Geyer, 2004). These theories explore non-linear relationships and the need for integration of different systems. Activity Theory (AT) (Engeström, 2001) draws on concepts from the socio-cultural psychological theories of Vygotsky and Bruner and has been widely applied to explain how the different systems align in health and social care (Daniels\& Edwards, 2010, pg1). It has also been used to explore the integration of patients in medical education (Regan de Bere \& Nunn, 2016) and has been applied to IPE (Anderson et al, 2014). Patient involvement in IPE, therefore brings together two Activity Systems (AS's); each has a set of interacting components to achieve a combined "Outcome". Ultimately the theory tries to deconstruct a complex activity identifying the components and their relationships. 
Over ten years using experiential learning and reflection, based on the Kolb learning cycle, we have built patient-centred IPL with ethical principles (Kolb, 1984; Anderson, Kinnair \& Ford, 2016). One example, is the one-day 'Listening Workshop', co-created by academics, patients and carers (Figure 1). Patients share their experiences with students in informal conversation for interprofessional reflection to identify good practice and areas for quality improvement (Anderson, Ford \& Thorpe, 2011). In the 'Listening Workshop' the AS describing the patients in emerging leading educator roles is brought alongside the AS describing IPE. Looking first at the AS as applied to IPE; the 'Subjects' are the students within their uni-professional curricula, the 'Object' towards which the activity is directed is the IPL. Much has been written about the challenges of IPE which must bring together diverse student groups often across different schools or HEIs. In AT these mediating influences are the 'Artefacts and Tools' which are influenced by the IPL processes. At the base of the triangle the 'Rules' which impact on IPE, including regulations, policies, professional standards, ethical codes and so on, which must be aligned for IPE. The, 'Community' comprises educators, students and participating service users as well as external bodies such as regulators. Finally, the 'Division of Labour' component of the model describes how the activity is managed and divided between the members of the community. In the AS describing IPE, participating patients are an educational resource sharing their stories for students to learn (Figure 2).

Insert Figure 1 and 2

Running in parallel is the AS describing the patients as both participants and leaders of the IPE for the 'Listening Workshop'. When we consider the components in the 
AS which describe patient involvement, the patients become the 'Subject' as they take on leading teaching roles; this is the focus of our research. The 'Object' is the IPE enhanced by the leading role of patients and the 'Artefacts and Tools', which now include the support processes for patients' involvement within faculty. At the bottom of the pyramid the 'Rules' will be similar but also include employment legislation and ethical issues relating to patient involvement. Patients now have a different role within the 'Community' as educators. Similarly in the 'Division of Labour' they take on new roles including teaching design, delivery and assessment.

Confident in this educational model (Listening Workshop), we explored the views of students, patients and teachers on progressing service users from telling their stories on to a leadership teaching role. We wanted to understand if patients and carers could lead the teaching by taking responsibility for pre-classroom preparation and for the teaching process of shaping student understandings thus moving beyond sharing experiences. AT was used to explore the complexity involved.

\section{Methodology}

This exploratory research aimed to explore perceptions concerning the progression of patients into leading teaching roles in the Listening Workshop. This teaching is delivered throughout the year and embedded in a range of health and social care undergraduate curricula.

We used a Participatory Action Research (PAR) approach which gathered qualitative data to listen to the experiences, meanings and reality of all the stakeholders 
involved in the workshop (Kuper, Reeves \& Levinson, 2008). A PAR design enabled a research partnership between the stakeholders and researchers, overseen by a steering group (Reason \& Bradbuty, 2008; Taggart 1991; Lewin, 1946). The researchers worked together with the stakeholders gathering information iteratively during one academic year. The results and outcomes were shared throughout the process with the participants and clarification was constantly sought by the researchers (ES/JS).

\section{Data Collection}

At the outset consultation meetings were established. Service users and academic leads (medicine, speech and language therapy, nursing and social work) took part in a series of consultation meetings at the beginning, middle and end of the process. The service users who attended these sessions had been involved in the workshop since its development and had taught for more than one year. The academics had overall responsibility for organising this IPE. Attendees worked in small groups responding to prompt questions on posters and post-it notes. The key outcomes from each group were shared, agreed and documented. The findings of the consultation meetings informed the content of the wider qualitative data collection from stakeholders (interviews and focus groups).

The stakeholders were those directly involved in the workshops, comprising the attending students, the patients telling their stories and the IP facilitators. Patients and IP facilitators were purposefully selected following informed consent. Service users were invited from a database of 60 names. IP facilitators were contacted from 
a list of 10 regular tutors. Students were invited to focus groups at the end of the workshops, leading to an opportunistic sample. Qualitative data were obtained using focus groups (with the students) and one-to-one interviews (with patients and IP facilitators). The interviews and focus groups were semi-structured, audio-taped discussions, lasting approximately forty-five minutes. They were conducted by an independent researcher. The data were collected until saturation was reached when no new findings emerged or where we had accessed as many students as were available (Guest, Bunce \& Johnson, 2006).

The data from the consultation group and stakeholders (patients, students and IP facilitators) were reported to the steering group which comprised the IPE academic leads, researcher and service user representatives. The steering group fed back to the next meeting of the consultation group to inform so that together the emerging ideas were refined. Data were therefore collected in parallel connected cycles from all stakeholders as outlined above (Figure 3). In this way the data emerged iteratively throughout the process.

INSERT FIGURE 3 HERE

\section{Data Analysis}

The data were transcribed into Microsoft Word using techniques to preserve the naturalness of the conversations, for example, unintelligible speech, fillers such as ‘um’ and non-verbal sounds such as laughter (McLellan, MacQueen \& Neidig, 2003). 
Data were analysed using thematic analysis focussing on views of patients taking on leading educational roles (Braun \& Clarke, 2006). Data from each stakeholder group were initially analysed separately. This involved two researchers (ES \& JF) becoming familiar with the material prior to coding by identifying meaningful segments. The researchers adopted an open approach of gathering and sorting meaningful elements, regardless of overlaps and contradictions, taking care to retain the context of these extracts. Subsequently the data were sorted into prototype themes and further refined by debate and discussion to seek agreement. This reviewing process continued to look for associations which identified the themes and subthemes leading to a hierarchy of meaning. In the final stage of the analysis the data from each group were compared, to identify common themes and themes specific to each group. In this way the data were triangulated and synthesised as the different perspectives were layered together.

Ethical permission was granted in the form of an extension to the regional ethical committee (COREC, 05/Q2502/104) evaluation of the local IPE curriculum.

\section{Results}

The consultation meetings welcomed twenty-one people (first $n=8$, second $n=15$, third $n=5$; sixteen were patients and five were tutors). Of these attendees three tutors and five patients subsequently gave interviews. An additional four patients gave interviews but were not able to attend the consultations making a total of nine patients. 
Forty students participated in focus groups (midwives $n=4$, speech and language therapy $[S L T] n=3$, nurses $n=8$, medical students $n=18$, social work [SW] $n=7$ ). On the majority of occasions two professions attended, however, on one occasion there were only social work students present.

The 9 patients who were interviewed comprised 4 people disabled by stroke ( 2 have aphasia), 2 adults with life-long disabling conditions, 1 young adult with an acquired disability, 1 parent of a disabled child and 1 carer of a young disabled adult.

The outcomes concerning views on patients in leading roles were "layered" leading to a consensus on two new roles for experienced participants. There was agreement that, with training, some patients would be able to lead student workshops in a "Co-Tutor" role, alongside experienced academic tutors. A second role, "Mentor", was proposed to support participating patients and recruit and induct others. There was a strong shared understanding between patients and tutors over how these roles might support the workshop. Our data showed that students had a more limited understanding and could only envisage patients contributing to teaching aspects of the workshop. The following sections explore the data in detail.

\section{Main findings from interviews and focus groups}

There were themes common to students, tutors and patients and distinct themes specific to each group. 
Three main themes were common to all stakeholders. First, perceptions that patients as teachers is a 'good thing', second, a belief that patients would require 'training' and, third, that leadership roles are 'not for everyone'. Although there was agreement there were some differences in the reasons for these perceptions in the different stakeholder groups. These three themes are discussed in turn.

Everyone agreed that it is a good thing for students to learn from patients as their experiences are authentic, giving them authority. Tutors recognised that patients' personal experiences give them a validity that tutors don't have.

"I don't stand up at the front of the class and say I faced brain surgery... I don't know what it's like to have gone through nights and nights of dealing with disabled children. I have no personal depth of understanding like these people," (Tutor 3).

Students identified that they would benefit through enriched and motivational learning, affirmed by patients.

"Having a bit of a feisty discussion with them is brilliant and brings it all back to life," (Student focus group).

"As a medical student I found it was very very useful as I am now able to improve my communication and listening skills," (Student focus group).

“There are certain things that wouldn't come to your mind unless you've gone through the system and you've had trouble doing it," (Patient). 
Tutors and patients identified benefits in terms of personal growth, feeling valued and opportunities for paid employment.

"They wanted to send me to a day care centre I said I am not going to play bingo, I don't want to play bingo. I said I want to do something useful...", disabled adult

"The more roles they take on the more empowering that might be for them...for some we might provide a step back into the sort of confidence they need to get employment...", (Tutor 3 ).

"I've become more self-confident and self-assured...," disabled service user.

"For us ourselves I feel it would be a real confidence boost", (Disabled adult).

"The problem is you do end up just feeling a bit like you're a specimen... but if you're a co-tutor it gives you more authority", (Disabled adult).

All agreed that leadership teaching roles for service users could be beneficial to students, patients and the University. Universities would gain additional patient involvement to embed service users' perspectives within curriculum design.

"...the patient as the expert...I think it would be very useful to back that up by having patients teach us because we're here to learn from them," (Student focus group).

"We want the students to end up in the service users' shoes understanding it from their perspective", (Tutor 1 ).

"I think the uni ...could use service users more to integrate them into university cause you know you're trying to explain the situation to someone and unless it's come from the person it's happened to...", (Student focus group). 
"I think it [patient as co-tutor] would give the right message across to students...", (Student focus group).

All stakeholders agreed that patients would require training. Patients were acutely aware they did not know very much about the content of professional curricula and tutors recognised they would need help in understanding how teaching is designed and delivered. Students were worried about patients who are not professionals leading teaching, meaning that students might miss out on specific content to facilitate their learning needs. They recognised that patients might feel lost and vulnerable in leadership roles and possibly unable to manage the teaching process.

"I think the biggest thing that they would need would be how to manage unruly students or students that don't want to engage and how to support ... and it's providing them with the tools to manage that", (Tutor 3).

"I do think there are some of these patients who have got the skills with time, with support to stand up and run the days", (Tutor 1 ).

"They might need training about presentation skills, producing a lecture... those sorts of areas", (Student focus group).

"If they did have the training say for the first session or two that they ran if there was a tutor there... an actual clinical tutor...to observe them and then give them feedback... and then after that if they were deemed competent to run those sessions", (Student focus group). 
"It would be helpful as well if they had a brief overview... of each of the students, what they actually did and what their training entails", (Student focus group).

All perceived that leadership is not for everyone. Several patients stated they wanted to continue to help healthcare students but not take on further leadership responsibilities. They were happy to share experiences but they felt unable to take on a commanding role in teaching. Students expressed doubts as they were fearful of chaotic teaching and described some patients as 'passive' and possibly incompetent. Tutors reflected that some patients would make ideal teachers while recognising that leading teaching was not for everyone.

"I'm not entirely sure how I might be able to cope", (Disabled adult).

“...it's about confidence building skills... they would need help...”, (Tutor 2).

"I could see her doing that role as a facilitator with a lecturer quite well...I think she was in a better place then maybe some of the other service users," (Disabled adult).

Distinct themes emerged from the three groups. Tutors were concerned about teaching quality and practical organisational issues, for example, service users and carers managing diverse student groups. They were particularly concerned about the management of the sensitives of IPE. 
"They need to understand about interprofessional education and some of the challenges of working with mixed groups of students...that takes some experience to handle," (Tutor 3).

"There's lots to be done in the morning before the students turn up... When we spoke to some of the service users a few weeks ago they said 'I might have issues with the children and I might not be able to make it', (Tutor 1).

“...we sometimes underestimate how exhausting a day of teaching can be", (Tutor 2).

Patients talked about the stress of participating in student teaching when this involved sharing their experiences and from this stance they recognised the need to "mentor people". They discussed helping to recruit new people and going on to advise and support them in starting to speak to students.

"but it can be a bit traumatic for the client to re-live those things and you know.....you go in and you're alright and you come out and actually feel because you've brought it all, the stuff, back which can affect your coping mechanisms", (Parent of a disabled child).

"I see myself mentoring people because I now feel as l've had enough experience of doing the Listening Project or talking to students to be able to sort of help other people and advise people...", (Carer). 
Students were concerned about having teachers who were unfamiliar and did not have a professional background. They expressed reservations about the competence of service users in a position of responsibility. They also felt they would not have built up a trusting relationship.

"Our tutors are medical professions to some degree or another so they can tailor or they can at least push us in a direction where it facilitates our learning where I imagine that a patient has more of an agenda of being a service user...and might not necessarily be directed directly to our learning needs," (Student focus group).

"Service users may not be able to understand some of the aspects in a student perspective way", (Student focus group).

"I think there would be some concern over leadership because none of the service users seemed to be kind of taking responsibility, they all seemed to be quite passive", (Student focus group).

"I would rather have a tutor even if it was just supervisory", (Student focus group).

"It would be quite daunting to rock up and be faced with a load of students", (Student focus group).

Students expressed a fear that patients would have their own agenda and may be prejudiced against certain professions. 
"They may have discriminatory reasons towards one profession... and then it might just turn into a profession bashing session," (Student focus group).

As the data from the stakeholder groups were triangulated three overarching themes emerged (Figure 4). These were, legitimacy, reservations and, the need for support. Pre-dominantly, legitimacy, there was a shared recognition that patients have the right to speak from their lived experiences of health and social care. Tutors, students and patients themselves understood this legitimacy. All expressed the conviction that personal experiences have greater impact and authenticity than "textbooks".

"Watch someone who isn't disabled talk about it, then watch me talk about it and I find that people listen to me," (Disabled adult).

"I think it's their right ...to design what they want to actually teach and what they want to tell," (Student focus group).

"I have no personal depth of understanding that these people have got so if they can command attention from the students I think they could be better teachers than myself," (Tutor 1 ).

INSERT Figure 4 Here

The second overarching theme related to reservations, these reservations fall into two categories, reservations concerning patients' potential competence, and reservations about potential depth of understanding of the requirements for 
professional education. Student and tutors expressed some doubts concerning patients' abilities to deliver interprofessional teaching unsupported. There were concerns over technical competence and whether some service users might be too emotionally vulnerable.

"I don't know if they will be good at organising students into groups or they will be completely terrible and the whole day would be chaotic," (Student focus group).

"Whether the emotional and physical toll of it is too much for them. I think we sometimes underestimate how exhausting a day of teaching can be," (Tutor 2).

These reservations were acknowledged by patients concerned that they might not cover the right teaching material and not know the right things to do. This leads directly into the final overarching theme that these reservations might be addressed through training and support. The tutors recognised that preparing patients would require time and input, for example;

"...I guess the other practical things like computer skills might be challenging but I am sure we could get there" (Tutor 1 ).

Some students expressed fears that patients in positions of power would pursue a biased personal agenda due to their own experiences.

"Also some patients you know may have particularly bad experiences with the health service so the teaching ...... will be aimed at their bad experiences and how all services are really bad", (Student focus group). 
The main themes and overarching themes bring together the perspectives of patients, educators and students revealing a multi-faceted picture of what it means for patients to progress into leading teaching roles in IPE. The themes illuminate the complexity within the components of AT. These relationships, as shown in Figure 4, highlight the consensus and tensions which emerged from the different stakeholder perspectives relating to trust, ability and yet the added value patients bring. The main findings of this research identify the possible vision of the combined AS's for IPE with patients in leading teaching roles (Figure 4).

\section{Discussion}

Patients were involved in telling their stories in this IPE event for many years. Our research considered the ability of these patients to take on leading teaching roles within this interprofessional workshop. This work involved the combining of an AS for IPE with that of Patent involvement towards the aspirational Outcome of the combined systems for patient-centred value-based collaborative practice. Our findings reveal unexpected tensions between the stakeholder's perceptions and highlights some ambivalent attitudes towards patients becoming faculty members. However, there was overall agreement on the legitimacy of their contribution to students' education. There was also agreement with some reservations on their ability to progress onto leading teaching roles. These reservations differ between stakeholders. Patients had a realistic appreciation of their training needs and that leadership was not for everyone. Students were far more ambivalent, tutors welcomed the progression mindful of patient support needs. 
Students perceived the impact of the "raw" and "emotional" patient story, giving them the right to teach, however, they expressed an expectation that patients' negative experiences could lead to bias and prejudice. There was a conflict between their perceptions of validity and their distrust of a potentially biased agenda and patients' potential incompetence. Students compared patients to trained professional teachers who have the expert knowledge of the curriculum, but not the insight into using services. When asked to picture service users and carers in leading roles students expressed far more trust in professional teachers ("god like") who understand the professional perspective and educational procedures. Students attempted to resolve these tensions by suggesting that both a patient teacher and a trained teacher should be present to achieve balance and insight from both sides. In one focus group these student discussions proposed the 'perfect teacher' who was both a patient and a professional with teaching qualifications. There is clearly an issue with trust when patients step up to take on a leading role, compounded by the fact that students rarely see disabled people in positions of authority. There are strong messages here about how students are prepared to be taught by patients and carers.

All participating students, medicine, nursing and midwifery, therapists and social workers had a limited understanding of the infrastructure around teaching and seemed unaware that support and training would be offered. Students were naïve apparently assuming that patients might be asked to teach without any preparation, as it did not occur to them that mechanisms would be put in place to ensure support. 
This reflects their limited experience of the "behind the scenes" operational processes underpinning the quality of teaching and learning.

The patients themselves showed considerable insight into the realities and the additional knowledge and skills they would require. There was recognition that not everyone would wish to progress onto leading teaching roles. They insisted that they would only feel confident taking up leading roles if working alongside trained educators. They showed a realistic appreciation of their own limitations and lack of knowledge of the curriculum and the professionalism of university teaching. These themes echoed the reservations expressed by students but showed a much deeper level of understanding by the service users and a more constructive focus. Patients described a "Mentor" role in which their experience and insight could be used to support others, again reflecting their understanding of the support required. This proposed Mentor role was not originally envisaged by the teaching team and has now been incorporated into the workshop design. Mentors have gone on to recruit and support people interested in sharing their story to benefit student learning.

Although much of our findings can be mapped to AT, our findings revealed an emotional element which is outside the scope of AT but was an appreciable aspect of the study. For the patients this relates to our earlier work when setting up the Listening Workshop concerning the emotional cost of sharing personal experiences (Anderson, Ford \& Thorpe, 2011). This was reflected in the patients' design of the 'Mentor role' which drew on these experiences to inform the support they believed new participants needed. The strength of these comments surprised us as we 
believed good support mechanisms were already in place. Healthcare professionals are well aware of the challenges of managing their own emotional involvement when working alongside patients undergoing trauma (Mann, 2005). Despite the recognition that there can be negative outcomes when patients revisit experiences in teaching there is surprisingly little literature on this subject (Spencer et al., 2011). It is clear that students are uncomfortable when faced with patients' raw emotions and it is clear that re-living a past painful experience is emotionally draining for some patients. Our aspiration as teachers to bring real experiences to students should not give us permission to expose patients to further emotional harm. Similarly students need to be prepared to face strong emotions and manage their own reactions constructively. Preparation of both patients and students is essential to create a safe environment (Barnes. Carpenter \& Bailey, 2000).

It was less expected to find such an emotional response by students who expressed strongly anxiety even distrust of patients in leading roles. The tone of the focus groups did vary in this accord apparently depending on the student mix. Where medical and nursing students dominated a group negative attitudes were expressed more frequently. The group dominated by social workers was more accepting of patient in roles of authority. This is a tentative finding which requires further study.

The tutors currently responsible for the running of the Listening Workshop were very positive about the central role of patients and carers for this learning and the opportunities for progression. They were conscious of the practical management of the teaching, especially IPE and the logistical implications such as setting up the 
classroom. Due to the challenges of delivering the workshop for large numbers of interprofessional students tutors recognised that patients could be a resource to grow capacity, both by recruiting new participants and by joining the tutor team. The affirmation that patients can take on leading roles offers "a continuum" so that people who have told their story many times can progress into different roles within the workshop's organisation. Tutors similarly recognised the need for support and training and that certain attributes would be essential if patients progressed beyond telling their stories.

Despite aspirations in national policy and regulation of professional education, patients and carers are rarely fully accounted for in quality assurance and governance processes. This can be explained by the added complexity to the alignment of two already complex AS, towards an 'Outcome' for interprofessional learning led by patients, so that students might understand patient-centred valuesbased practice. The community engaged in this project is especially complex, comprising faculty, students and patients, aligned to two HEls and our local NHSpractice educators representing several professional schools. Therefore, we have set up new processes within the AS's of IPE and patient involvement to support the two new roles for patients; "Co-tutor" and "Mentor". A remuneration system for patient involvement with administrative oversight is now in place. Teaching timetabling processes include the scheduling of Co-Tutors. New training has been particularly important for both the Co-tutor and Mentor role. This training includes indepth discussion of the professionalism of teaching and insight into how teachers align learning outcomes with assessment, equality and diversity issues and so on (Anderson, Hean, O’Halloran, Pitt \& Hammick, 2014). Mentors now recruit and 
support new patient participants for the workshop. Patient Mentors and Co-Tutors now participate fully in the annual training for academic tutors on content and IP facilitation. Patients as Co-tutor have joined the teaching steering group ensuring full engagement in quality assurances processes.

There are limitations for this study in that it focusses on one patient involvement model and cannot necessarily be generalised to other teaching contexts. There were fewer participants than ideal as few tutors had sufficient experience to participate. Many students were unable to stay on after the workshops to participate in the focus groups. This means that the interprofessional mix varied from one group to another and the views of better represented student groups may have biased some discussions. It was not possible to include students in the steering group and consolation meetings. This work was time limited to one academic year.

The strengths of this study included the use of an independent researcher.

Strategies were in place to ensure inclusive conversations with patients, for instance the use of written notes (poster summaries), and recordings and we included several cycles of data collection to achieve clarification and agreement. The lead researchers were aware of their involvement in the teaching and adopted a reflective approach throughout. 
Our data suggest that despite the complex challenges of bringing these two AS together, it is achievable with faculty commitment and resources; this cannot be underestimated. Patients must be fully integrated into faculty whilst at the same time appropriately support in recognition of their possible vulnerability. Perhaps the greatest lesson is the finding that students may feel threatened if not fully prepared to meet patients in positions of authority. Patients in leadership roles is different from patients telling their stories. Students are very comfortable to hear patients' lived experiences, however, this does not mean they will be equally comfortable with that patient as tutor.

\section{Acknowledgement}

This work was funded by the UK Higher Education Academy

\section{References}

Anderson, E.S., Ford, J. \& Thorpe, L.N. (2011). Learning to Listen: Improving students' communication with disabled people. Medical Teacher, 32,1-9.

Anderson, ES., Kinnair, D, Ford, J. (2016). Interprofessional Education and Practice Guide No.6: Developing Practice-Based interprofessional learning using a short placement model. Journal of Interprofessional Care, 30(4), 433-440. http://www.tandfonline.com/doi/full/10.3109/13561820.2016.1160040. 
Anderson, E.S., Hean, S., O’Halloran, C., Pitt, R. \& Hammick, M. (2014). Faculty Development and Interprofessional Education and Practice. Chapter 14, 287-310, Pg 289. In: Steinert ,Y. (Ed) Faculty Development in the Health Professions: $A$ focus on Research and Practice'. New York: Springer.

Anderson, ES. \& Smith, R. (2010). Learning from Lives together: lessons from a joint learning experience for medical and social work students. Health and Social Care in the Community,18(3), 229-240. DOI: 10.1111/j.1365-2524.2010.00921.x

Arnstein SR (1969). A ladder of citizen participation. Journal of American Institute of Planners, 35(4), 216-224.

Australian Commission (2012). National Safety and Quality Health Service Standards. Sydney: Australian Commission on Safety and Quality Health Care. http://www.safetyandquality.gov.au/wp-content/uploads/2011/09/NSQHS-StandardsSept-2012.pdf

Barnes, D., Carpenter, J. \& Bailey, D. (2000) Partnerships with service users in interprofessional education for Community mental health: a case study Journal of Interprofessional Care, 14(2),189. 
Barr, H. (2013). Towards a theoretical framework for interprofessional education. Journal of Interprofessional Education, 27, 4-9.

Barr, H., Ford, J., Gray, R., Helme, M., Hutchings, M., Low, H., Machin, A. \& Reeves, S. (2017). Interprofessional education Guidelines 2017. CAIPE, Fareham.

Beresford, P., Branfield, F., Taylor, J., Brennan, M., Sartori, L.M. \& Wise, G. (2006) Working Together for Better Social Work Education. Social Work Education, 25(4), 326-331.

Braun, V. \& Clarke, V. (2006). Using thematic analysis in psychology. Qualitative Research in Psychology, 3, 77- 101.

Chochinov, H.M. (2007). Dignity and the essence of care: The A, B. C and D of dignity conserving care. BMJ, 335,184-187.

Cooper, H., Braye, S.\& Geyer, R.(2004). Complexity and interprofessional education. Learning in Health and Social care, 3(4):179-189. 
Daniels, H. \& Edwards, A. (2010). Introduction: In, Activity Theory in Practice:

Promoting learning across boundaries and agencies. Eds; Daniles, H., Edwards, A., Engeström, Y., Gallagher, T \& Ludvigsen, S.R. Abingdon \& New York: Routledge.

Francis, R. (2013). Report of the Mid Staffordshire NHS Foundation Trust public inquiry. London: The Stationery Office.

Department of Health. (2010). Equity and Excellence: Liberating the NHS. London: The Stationary Office.

Engeström, Y. (2001). Expansive theory at work: Towards an activity theoretical reconceptualisation. Journal of Education and Work, 14,133-156.

General Medical Education. (2011). Patient and Public involvement in undergraduate medical education: Advice supplementary to Tomorrow's Doctors (2009). London: GMC.

Gilbert, J. (2005). Interprofessional learning and Higher Education structural barriers. Journal of Interprofessional Care, 19(suppl 1), 87-106.

Guest, G., Bunce, A. \& Johnson, L. (2006). How many interviews are enough? An experiment with data saturation and variability. Field Methods, 18(1), 59-82. 
Health and Care Professions Council (2014). Standards of education and training. London: HCPC. http://www.hcpc-

uk.org/assets/documents/1000295EStandardsofeducationandtraining-

fromSeptember2009.pdf [accessed $15^{\text {th }}$ November 2016].

Health Canada (2007). Primary Care Healthcare Transition Fund. Collaborative Care. Ottowa: Health Canada. http://www.hc-sc.gc.ca/hcs-sss/alt formats/hpbdgps/pdf/prim/2006-synth-collabor-eng.pdf

Higginson, I.J. \& Hall, S. (2007). Rediscovering dignity at the bedside: It is possible to teach the $A B C D$ of preserving patients' dignity. BMJ, 335, 167-8.

Hutchings, H.A. \& Rapport, F (2012). Patient-centred professionalism Patient Intelligence, 4,11-21.

Kilminster, S.M., Stark, P., Hale, C., Lascelles, M., Morris, P., Roberts, T., Sowter, J. \&, Thistlethwaite, J (2004). Learning for real life: patient focussed interprofessionalworkshops do offer added value. Medical Education, 38, 717-726.

Kolb, D.A. (1984). Experiential learning - Experience as a source of learning and development. Upper Saddle River, NJ: Prentice Hall. 
Kuper, A., Reeves, S. \& Levinson, W. (2008). An introduction to reading and appraising qualitative research, BMJ , 333, 404- 407.

Lewin, K. (1946). "Action Research and Minority Problems", Journal of Social Issues, 2(4), 34-46.

Mann, S. (2005). A health-care model of emotional labour an evaluation of the literature and development of a model. Journal of Health Organization and Management, 19(4/5), 304-317.

McKeown, M., Malihi-Shoja, L. \& Downe, S. (2010). Service User and Carer Involvement in Education for Health and Social Care. CAIPE, Wiley-Blackwell: Oxford.

McLellan, E., MacQueen, KM. \& Neidig, JL. (2003). Beyond the qualitative interview data preparation and transcription. Field Methods, 15(1), 63-84.

National Health Service (2014). Five year Forward view. NHS England.

Nursing and Midwifery Council (2010). Standards for pre-registration nursing education. London: NMC. https://www.nmc.org.uk/standards/additional- 
standards/standards-for-pre-registration-nursing-education/ [accessed $15^{\text {th }}$ November 2016].

Reason, P. \& Bradbury, H. (2008). (eds) The Sage Handbook of Action Research: Participative Inquiry and Practice. Sage, CA.

Regan de Bere, S. \& Nunn S. (2016). Towards a pedagogy for patient and public involvement in medical education. Medical Education, 50(1), 79-92.

Spencer, J. (2016). Some activity but still not much action on patient and public engagement. Medical Education,50 (1), 5-7.

Spencer, J., Godolphin, W., Carpenko, N. \& Towle, A. (2011). Can Patients be teachers? Involving patients and service users in healthcare professionals' education. The Health Foundation: London.

Taggart, R. (1991). The principles of Action Research. Adult Education Quarterly, 41(3), 168-187.

Tew, J., Gell, C. \& Foster, F. (2004). A good practice guide. Learning from experience. Involving service users and carers in mental health education and 
training. Nottingham: Mental Health in Higher Education. National Institute for Mental Health in England/Trent Workforce Development Confederation.

Towle, A., Farrell, C., Gaines, M.E., Godolphin, W., John, G., Kline, C., Lown, B., Morris, P., Symons, J. \& Thistlethwaite, J. (2016). The patient's voice in health and social care professional education: The Vancouver Statement. International Journal of Health Governance, 21(1), 18-25.

World Health Organisation. (2010). Framework for action on interprofessional education and collaborative practice. Geneva, WHO. 
Figure 4: Outcomes of the Combined Activity Systems for Patient Involvement in Interprofessional Education
TOOLS: Teaching processes (Listening Workshop) additional processes to employ patients as Co-tutors and Mentors and support them

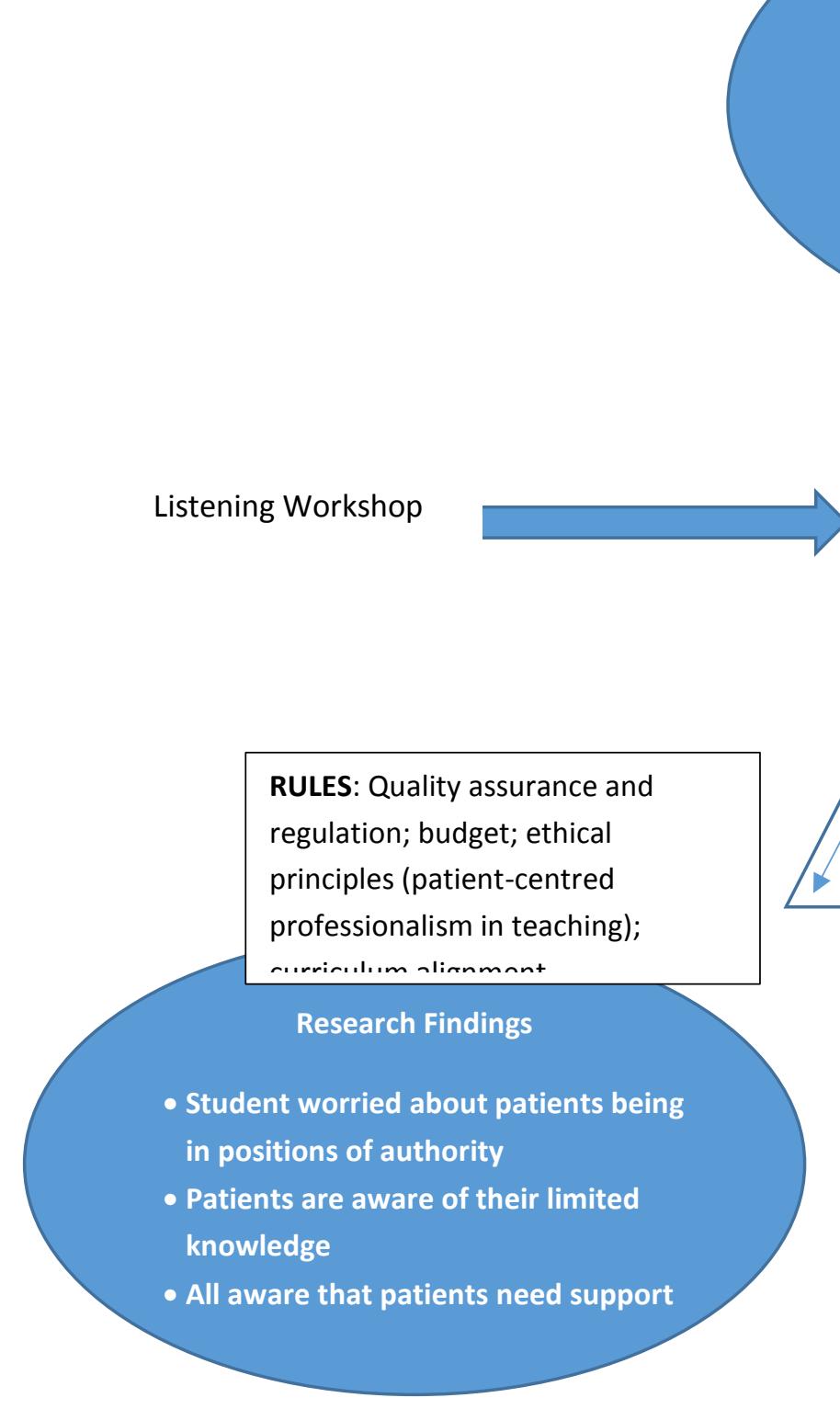

- Students unaware of background teaching

set up processes

- Educators value the potential help of Co-

tutor and see additional training and support

need

- Patients value progression to a leadership
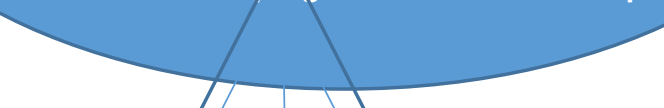

Learning through patientcentred Interprofessional education principles (patient-centre professionalism in teaching);

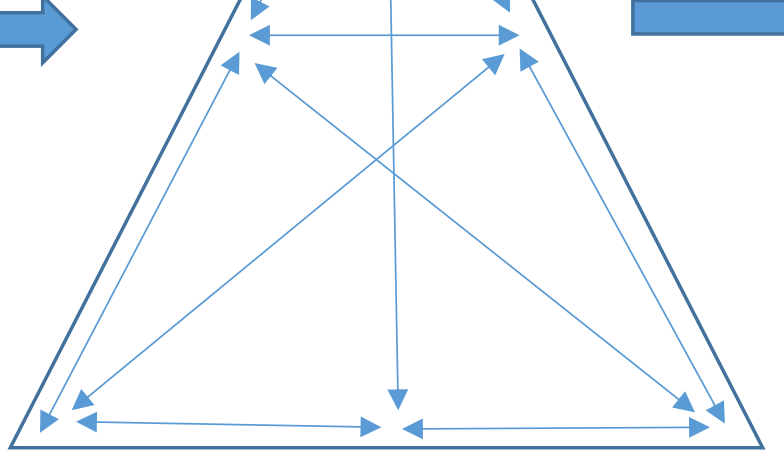

DIVISION OF LABOUR: Faculty educators and clinical teachers facilitation; administration; recruitment of service users

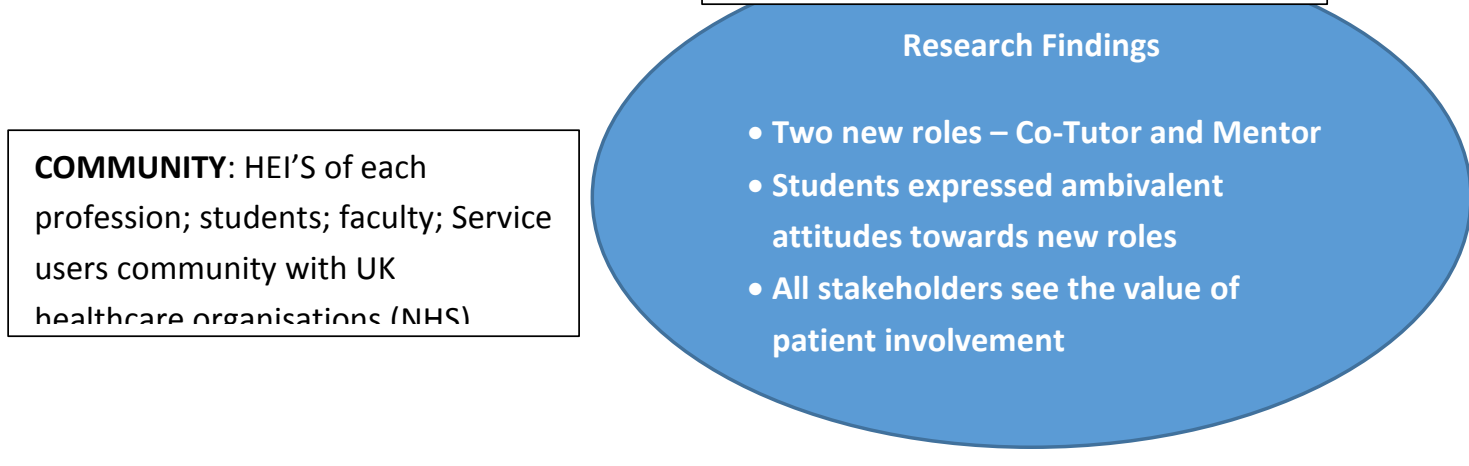

Adapted from Engeström Activity Theory (2001) 
Figure 1: The Listening Workshop aligned to the Kolb Learning Cycle

Students take their learning into practice

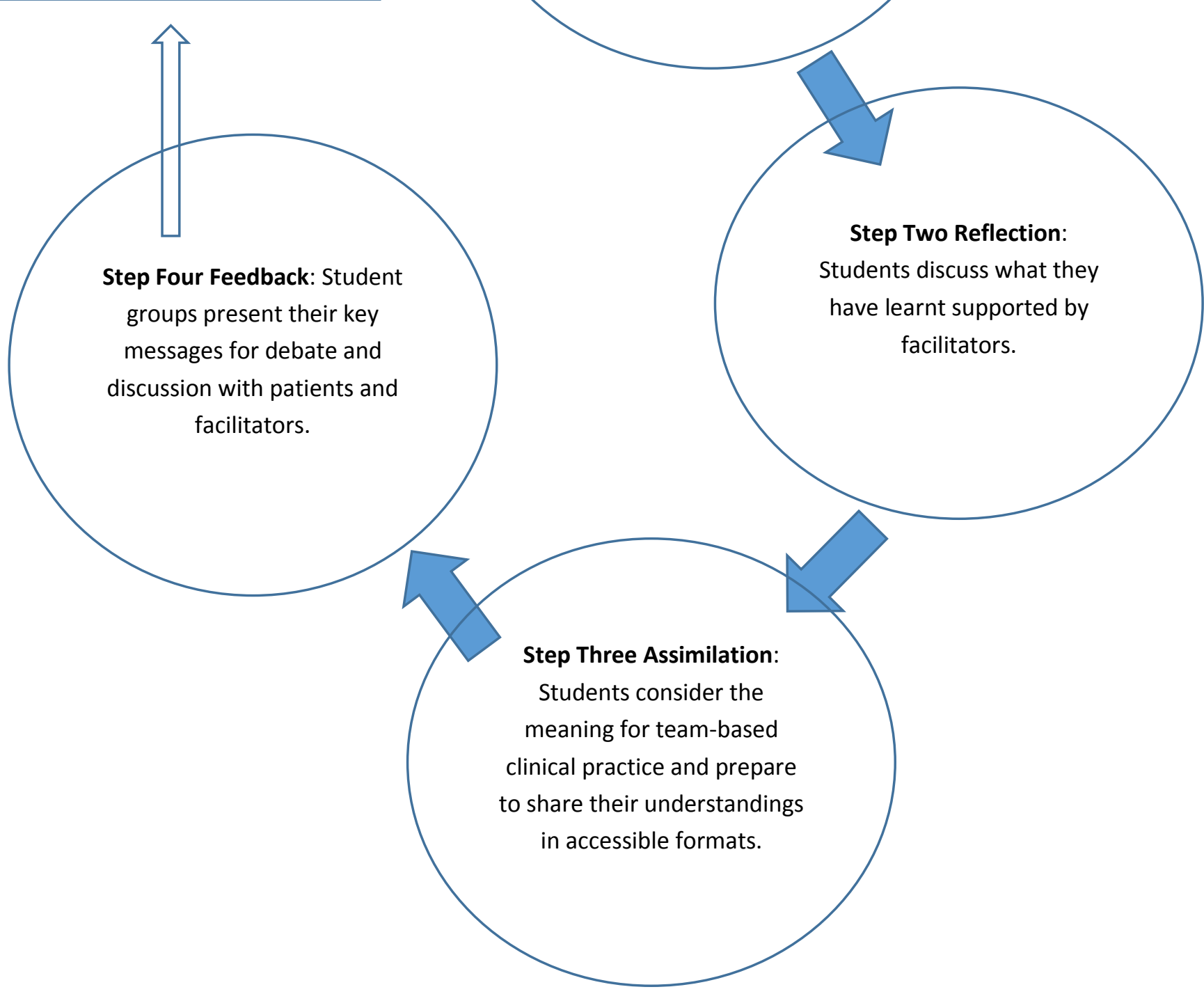


Figure 3: Outline of Project Stages (In 2014/15)

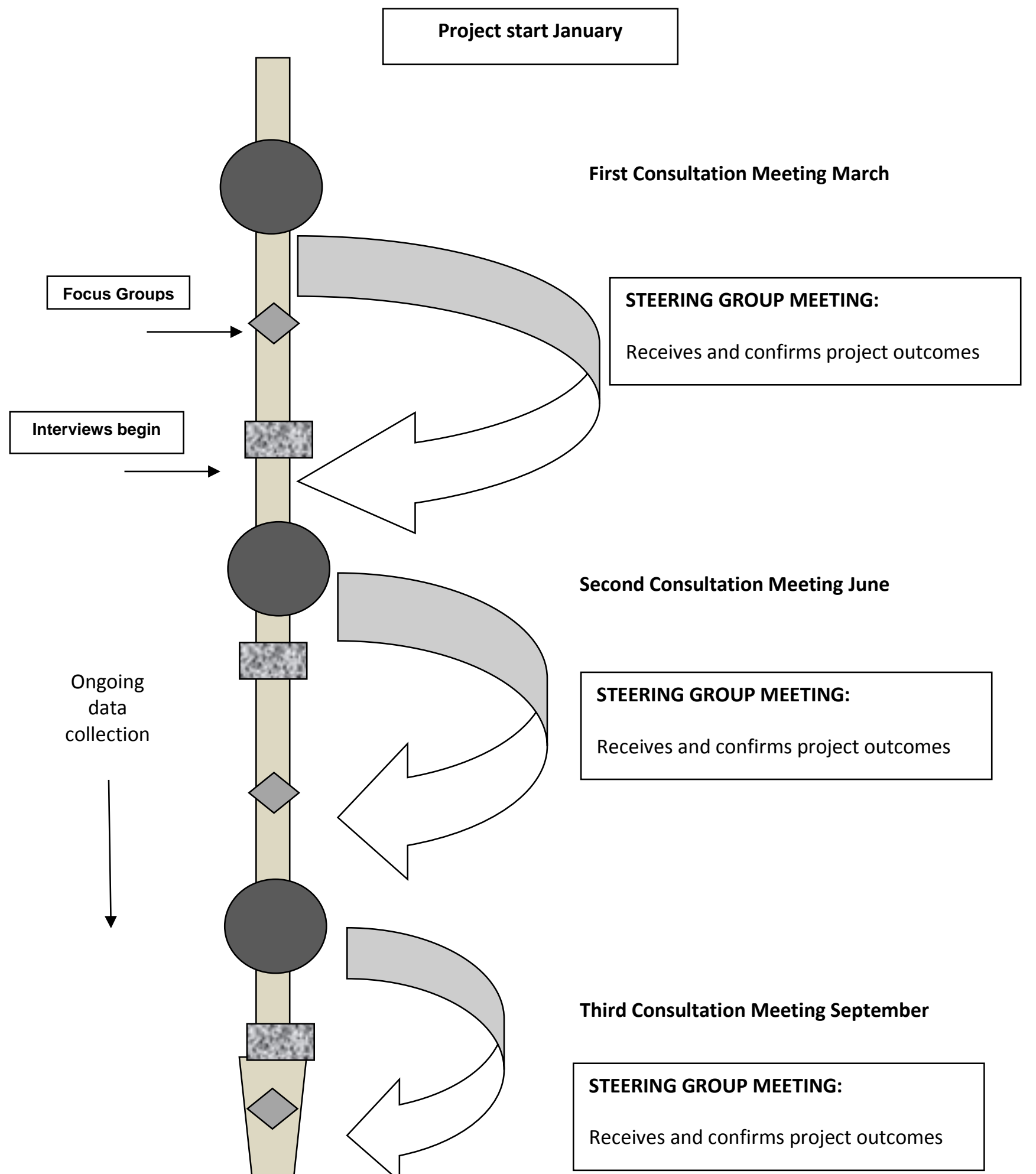


Final Project Agreement: New Roles and a supportive package for enabling service users to adopt these including training programmes agreed; observation opportunities evolving with evaluation on-going. Negotiations with the Community Trust for employment are on-going. 


\section{Artefacts and Tools}

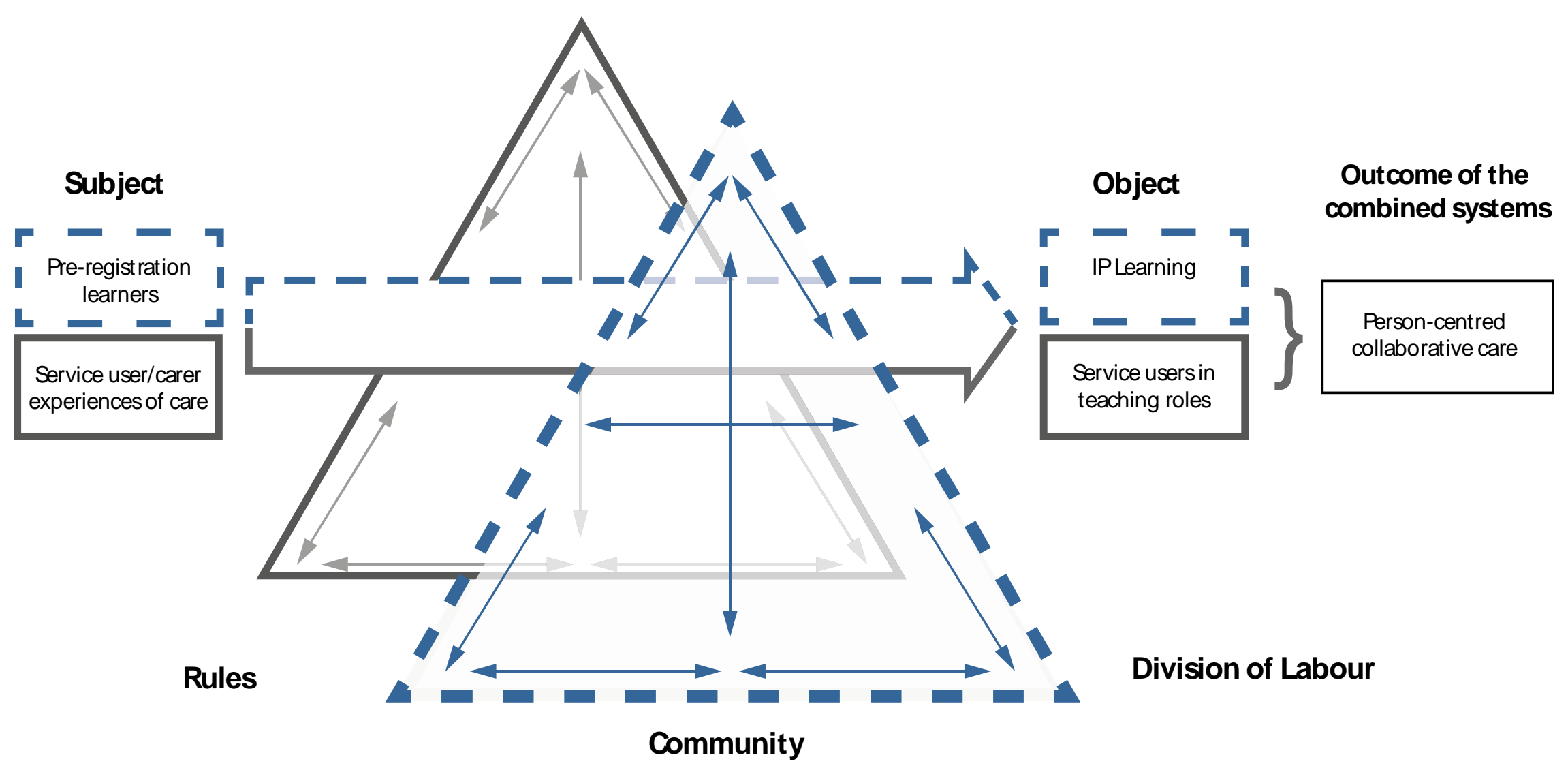

ᄂ

Activity system for Patient Involvement 